\title{
Effect of 90-90 Supported Hip Shift Hemibridge with Balloon Exercise on Primary Dysmenorrhea in Obese Undergraduate Females- An Experimental Study
}

\author{
Pranali Chougule ${ }^{1}$, Archana D. Methe ${ }^{2}$, Drashti Shah ${ }^{3}$, Ronald Prabhakar ${ }^{4}$ \\ ${ }^{1}$ B.P.Th. Intern, ${ }^{2,3}$ Assistant Professor, ${ }^{4}$ Professor, \\ MMC College of Physiotherapy, Wanless Hospital, Miraj, Maharashtra, India \\ Corresponding Author: Pranali Chougule
}

\begin{abstract}
Background: Dysmenorrhea is a painful menstruation which can affect daily activities. Primary dysmenorrhea is most common complaint without pathologic pelvic disease. The pain is dull aching, intermittent and located in suprapubic area and lower back associated with symptoms dizziness, headache, vomiting, and diarrhea. Obesity is associated with dysmenorrhea as adipose tissues affect the hormonal balance. Low back pain (LBP) is a common symptom in dysmenorrhea.

Objective: The purpose of this study was to evaluate the effect of 90-90 supported hip shift hemibridge with balloon exercise on primary dysmenorrhea in obese undergraduate females for pain.

Methods: This experimental study was conducted among 30 female subjects from undergraduate colleges of Miraj, Maharashtra, India. Females between age group of 18-25 years with BMI 25-29.9 $\mathrm{kg} / \mathrm{m}^{2}$ having primary dysmenorrhea with LBP were included in the study based on inclusion and exclusion criteria. Outcome measures used were VAS \& WaLIDD scales to assess for pain, daily activities and to diagnose dysmenorrhea. Further they were given 90-90 supported hip shift hemibridge with balloon exercise during first 3 days of menstruation and pre-post VAS was measured and WaLIDD score was compared with previous month score.
\end{abstract}

Results: The statistical analysis was done using paired t test which showed 90-90 hip shift supported hemibridge with balloon exercise was statistically significant on VAS and WaLIDD scores with ( $p$ value 0.000$)$.

Conclusion: 90-90 supported hip shift hemibridge with balloon exercise has shown to reduce low back pain in primary dysmenorrhea in obese females.

Keywords: Low Back Pain, 90-90 hemibridge, Obesity, WaLIDD.

\section{INTRODUCTION}

Dysmenorrhea

is painful menstruation of sufficient magnitude so as to incapacitate day-to-day activities which is a common problem of women in reproductive age. ${ }^{[1]}$

The pain is dull aching, intermittent and it is situated in suprapubic area and the back (low back pain) without any radiation. It is classified as primary and secondary. Primary dysmenorrhea is the one where there is no pelvic pathology. And secondary dysmenorrhea is considered as menstruation associated pain occurring in the presence of pelvic pathology. ${ }^{[2]}$ Dizziness, headache, tiredness, vomiting, and diarrhea all occur just before or during the menstruation within few hours along with dysmenorrhea. $^{[3]}$ Sometimes patient also experience premenstrual syndrome (PMS) and these symptoms start before the menstrual cycle and reduce shortly after 
menstrual flow begins here is associated with breast tenderness and abdominal bloating. Premenstrual syndrome and dysmenorrhea is discriminated on the basis of patient's history. ${ }^{[4]}$

Widely accepted etiology of primary dysmenorrhea is increased level of prostaglandins which stimulates myometrial hyper-contractility which causes ischemia and hypoxic effects in the myometrium and produces pain. ${ }^{[5]}$ These levels are highest during first two days of menstruation because of which the symptoms are highest in these two days. ${ }^{[6]}$ The symptoms start within hours before or at the beginning of menses and lasts for 24-48 hours. ${ }^{[7]}$ NSAID's \& oral contraceptives are used to treat dysmenorrhea. ${ }^{[8]}$

According to many studies the prevalence of dysmenorrhea around the world is between the range of $28 \%$ and 71.7\%. ${ }^{[9]}$ Also Indian studies have reported the prevalence of dysmenorrhea in India ranges between $50-87.8 \% .{ }^{[10]}$ According to Indian studies the prevalence of dysmenorrhea in the age group of 17-24 years is $67 \%$ to $90 \%$. ${ }^{[11]}$ Data from many studies have proved that absenteeism from school and colleges is $34-50 \%$ due to primary dysmenorrhea. ${ }^{[12]}$ It has been found that the females experiencing dysmenorrhea do not take medical or physiotherapeutic help instead they go for home remedies or take alternative methods or medicate themselves without any professional guidance/ prescription which may result in secondary effect. ${ }^{[13]}$ Table 1 shows Asian Pacific Classification of BMI (Body Mass Index). ${ }^{[3]}$

Table1. Asian Pacific Classification of BMI

\begin{tabular}{|l|l|}
\hline Nutritional status & BMI $(\mathbf{K g} / \mathbf{m} 2)$ \\
\hline UNDERWEIGHT & $<18.5$ \\
\hline NORMAL & $18.5-22.9$ \\
\hline OVERWEIGHT & $23-24.9$ \\
\hline OBESE I & $25-29.9$ \\
\hline OBESE II & $>30$ \\
\hline
\end{tabular}

According to conventional $\mathrm{WHO}$ classification: Obesity: BMI $>30 \mathrm{~kg} / \mathrm{m} 2$, Overweight: BMI $23.1-29.9 \mathrm{~kg} / \mathrm{m}^{2}$, Normal: BMI $18.5-23 \mathrm{~kg} / \mathrm{m}^{2}$. ${ }^{[3]}$
In India with more than 1 billion population there is a trend of increasing prevalence of obese/overweight people. ${ }^{[14]}$ The prevalence of overweight/obesity has increased from $13 \%$ in $2005-06$ to $21 \%$ in 2015-16 with highest in females. ${ }^{[15]}$

There is a complex relation between body fat and steroid hormones. There are many studies which prove the relationship between BMI and dysmenorrhea. ${ }^{[16]}$ Certain amount of body fat is important to maintain normal ovulatory cycles, excess or inadequate fat results in disturbance of reproductive health. ${ }^{[17]}$ It has been proved that overweight or obesity also plays an important role in etiology of primary dysmenorrhea. ${ }^{[18]}$ Increased adipose tissues disturb the balance of estrogens, androgens, prostaglandins and other sex-bound hormones (SHBG). The capacity of estrogen to bind with sex hormones decreases which results in increase level of estrogen and inactivated estrogen and so increases serum estradiol level. ${ }^{[17]}$ The adipose tissues regulate the production \& release of androgens so overall excess of adipose tissues increases androgen and estrogen level thus causes uterine hyper contractility results in painful menstruation. ${ }^{[19]}$

Low back pain (LBP) is a very common symptom in dysmenorrhea experienced by young girls. ${ }^{[20]}$ Studies have found that $40-50 \%$ of the young girls experience LBP during menstrual phase (16 days). It has been said that during menstruation hormonal imbalance which affects the collagen synthesis causing ligament laxity in the facet joints affecting the spinal instability causing menstrual LBP. ${ }^{[21]}$ As 90-90 supported hip shift hemibridge with balloon exercise has been proved to be effective in low back pain. ${ }^{[22]}$ This exercise is developed by Postural Restoration Institute (PRI) to improve breathing along with posture and stability to reduce back pain. ${ }^{[23]}$ By performing this exercise all the core muscles gets activated and also provide optimal ZOA (zone of apposition) of diaphragm so that focuses on 
LBA (low back ache) by improving pelvic and core stability. ${ }^{[24]}$

Prevalence of dysmenorrhea in college going females was found $79.66 \%$ in which underweight and obese females are more prone to dysmenorrhea with symptoms of low back pain. Previously done studies have treated low back pain using 90-90 hip shift with hemibridge and balloon exercise and they have proved that this exercise is effective.

Also, previously done studies have few literatures that show the effect of exercise on primary dysmenorrhea in obese females. Thus this study is been conducted using 90-90 hip shift with hemibridge and balloon exercise in obese females with symptoms of low back pain in primary dysmenorrhea.

The aimed to find the find the effect of 90-90 supported hip shift hemibridge with balloon exercise on primary dysmenorrhea in obese undergraduate females. The objective of the study was to evaluate the effect of 90-90 supported hip shift hemibridge with balloon exercise on primary dysmenorrhea in obese undergraduate females.

\section{MATERIALS AND METHODS}

30 females from undergraduate colleges of Miraj, Maharashtra, India participated voluntarily in this study. The participants were selected based on the inclusion criteria that is age group of 18-25 years, BMI $25-29.9 \mathrm{~kg} / \mathrm{m}^{2}$ having primary dysmenorrhea. The exclusion criteria were cardiovascular, neurological, musculoskeletal, menstrual or psychiatric disorders. Ethical clearance was obtained from Institutional Ethical Committee of College of Physiotherapy, Wanless Hospital, Miraj Medical Centre, Miraj. The participants were briefed about the study and written informed consent and demographic data in the form of age, gender, BMI, marital status and menstrual regularity were taken from the participants.

Procedure: $90-90$ hip shift hemibridge with balloon exercise was performed by the participants during menstruation for 3 sessions for first 3 days during menstruation.

Instructions for exercise:

1. Lie on your back with your feet flat on a wall and your knees and hips bent at a 90-degree angle.

2. Place a 4-6 inch ball between your knees.

3. Place your right arm above your head and a balloon in your left hand.

4. Inhale through your nose and as you exhale through your mouth, perform a pelvic tilt so that your tailbone is raised slightly off the mat. Keep your low back flat on the mat. Do not press your feet flat into the wall instead dig down with your heels.

5. Shift your left knee down so that it is below the level of your right without moving your feet and press your left knee into the ball. You should feel your left inner thigh engage.

6. With your left knee shifted down; take your right foot off the wall. You should feel the back of your left thigh engage. Maintain this position for the remainder of the exercise.

7. Now inhale through your nose and slowly blow out into the balloon.

8. Pause three seconds with your tongue on the roof of your mouth to prevent airflow out of the balloon.

9. Without pinching the neck of the balloon and keeping your tongue on the roof of your mouth, inhale again through your nose.

10. Slowly blow out as you stabilize the balloon with your hand.

11. Do not strain your neck or cheeks as you blow.

12. After the fourth breath in, pinch the balloon neck and remove it from your mouth. Let the air out of the balloon.

13. Relax and repeat the sequence 4 more times. 


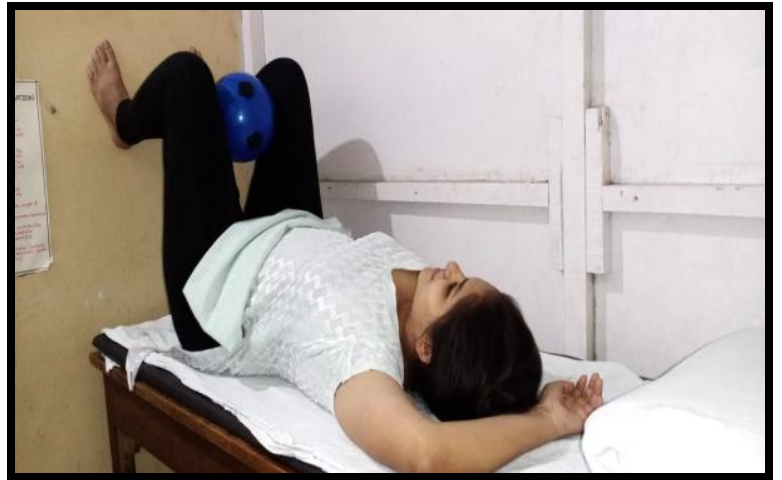

Fig. 1: 90-90 supported hemibridge

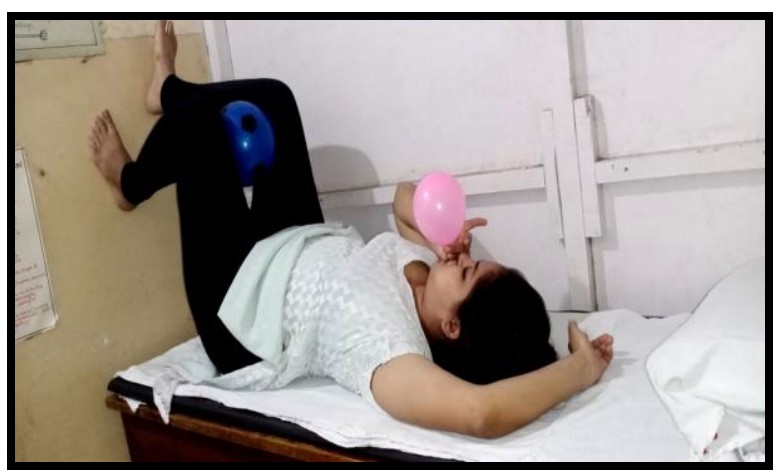

Fig. 2: 90-90 supported hip shift with ball and baloon
The assessment of pain was done by using Visual Analogue Scale (VAS) and WaLIDD (Working ability, Location, Intensity of pain, Days of pain and dysmenorrhea) scale.

Visual Analogue Scale (VAS): The pain intensity was measured using VAS scale using $10 \mathrm{~cm}$ line where 0 represents no pain and 10 represents worst pain $(\mathrm{r}=0.99) .{ }^{[25]}$

WaLIDD Scale: The scale has following components which explain the features of dysmenorrhea 1) Working ability; 2) Anatomical pain location; 3) Intensity (Wong-Baker scale); 4) Days of pain. This scale was used to diagnose dysmenorrhea in obese females in this study. Reliability 0.951-0.997. ${ }^{[26]}$ Table 2 shows the score variables of WaLIDD scale.

Table 2: Score Variables of WaLLID scale

\begin{tabular}{|l|l|l|l|}
\hline Working ability & Location & Intensity(Wong-Baker) & Days of pain \\
\hline 0. None & 0. None & 0. Does not hurt & 0.0 \\
\hline 1. Almost never & 1.1 site & 1. Hurts a little bit & $1.1-2$ \\
\hline 2. Almost always & $2.2-3$ sites & 2. Hurts a little more - hurts even more & $2.3-4$ \\
\hline 3. Always & 3.4 sites & 3. Hurts a whole lot - hurts worst & $3 .>/=5$ \\
\hline
\end{tabular}

Equipments used: Weighing machine, measuring tape, squeez ball (4-6 inch) and balloon.

Statistical Analysis: All statistical analysis was done by using SPSS 16.0 for windows. The level of significance was set at $\mathrm{p}=0.05$. Descriptive analysis was used to calculate mean and standard deviation. Paired $t$ test was performed for intragroup scores.

\section{RESULTS}

Pre and post intervention values of VAS and WaLIDD in undergraduate obese females receiving 90-90 hip shift hemibridge with balloon exercise were analyzed using paired $t$ test. The demographic details in the group were homogeneous with $\mathrm{p}>0.05$.

Table 3 represents the mean and standard deviation of age, height, weight and BMI (demographic data) of young obese females which were included in this study.

Table3. Demographic data

\begin{tabular}{|l|l|l|}
\hline Variables(n=30) & Mean & Std. Dev. \\
\hline Age(years) & 21.77 & 1.36 \\
\hline Height(m) & 1.59 & 0.05 \\
\hline Weight(kg) & 69.73 & 5.90 \\
\hline BMI & 27.6 & 1.65 \\
\hline
\end{tabular}

Table 4: Descriptive statistics of young obese females receiving 90-90 supported hip shift hemibridge with balloon exercise on pain in primary dysmenorrhea using VAS and WaLIDD scales.

\begin{tabular}{|c|c|c|c|c|c|c|c|c|}
\hline Variables & \multicolumn{4}{|l|}{ VAS } & \multicolumn{4}{|c|}{ WaLIDD } \\
\hline $\mathrm{N}=\mathbf{3 0}$ & Mean & Std. Dev & $\mathrm{CV}$ & P value & Mean & Std Dev & $\mathrm{CV}$ & P value \\
\hline Pre treatment & 6.8 & 1.19 & 17.44 & \multirow[t]{2}{*}{0.000} & 7.13 & 1.31 & 18.31 & \multirow[t]{2}{*}{0.000} \\
\hline Post treatment & 3.6 & 1.04 & 28.81 & & 4.77 & 0.97 & 20.38 & \\
\hline
\end{tabular}

Out of 30 obese females $10 \%$ of them had irregular menstrual cycle and $90 \%$ had regular menstrual cycle. The study showed excellent significance of exercise to reduce pain via VAS and WaLIDD scales 
during menstruation as shown in Table 4. No adverse effects were reported.

Thus, alternative hypothesis $\left(\mathrm{H}_{1}\right)$, significant effect of $90-90$ hip shift hemibridge with balloon exercise on obese females with primary dysmenorrhea is accepted.

\section{DISCUSSION}

This study used 90-90 supported hip shift hemibridge with balloon exercise to treat low back pain in primary dysmenorrhea in obese females. The outcome measures for pre and post intervention in this study (VAS and WaLIDD) has showed an excellent statistical significance. According to the previous studies obesity plays major role in dysmenorrhea as increased amount of adipose tissues disturbs the hormonal levels in the body. Increased level of adipose tissues disturbs the balance of oestrogen, prostaglandins and also other Sex bound hormones (SHBG). Thus increases the uterine hyper contractility resulting into painful menstruation. ${ }^{[17,18]}$

Low back pain (LBP) is the commonest symptom experienced by young girls during menstruation $(40.1 \%$ and $17.6 \%) .{ }^{[20]}$ About $35-50 \%$ school or college absenteeism is observed because of painful menstruation as it interferes with daily activities. ${ }^{[12]}$ By some authors it was hypothesized that menstrual LBP is may be due to spinal instability resulting from ligament laxity due to hormonal imbalance which affects collagen synthesis. Ligament laxity affects the passive subsystem of the spine which is an important aspect for maintaining stability of the spine. ${ }^{[27]}$ Thus, lumbar stability is an important factor in menstrual LBP. Thus, this study focused on treating LBP in primary dysmenorrhea in young obese females. The 90-90 supported hip shift hemibridge with balloon exercise used in this study focuses on the lumbar stability by promoting optimal posture. It also concentrates on the activation of core muscles that is abdominal muscles including transverse abdominal and oblique muscles which may contribute to the lumbar spine stability which is affected during menstruation due to ligament laxity. Therefore, activation or strengthening of these muscles is a key to reduce LBP by improving lumbar stability. This can be a protective mechanism for lumbar spine.

This exercise demands blowing of balloon while performing the procedure during exhalation, blowing the balloon during exhalation helps in activation of the abdominal muscles and inhibition of paraspinal muscles by targeting the Zone of Apposition (ZOA) of the diaphragm during exhalation to an optimal position. This exercise causes slow breathing and further relaxes neuromuscular system and decreases the resting muscle tone.

The synchronized activity of diaphragm and abdominal muscles helps to maintain respiration as well as lumbar stability, as diaphragm plays an important role in stabilization of lumbar spine. Contraction of the diaphragm helps the abdominals and pelvic floor to increase the intra abdominal pressure (IAP). IAP helps to stabilize the spine.

While performing this exercise, during inhalation the concentric contraction of diaphragm and eccentric contraction of abdominals while during exhalation through balloon concentric contraction of abdominals and eccentric contraction of diaphragm improves the strength of these muscles and thus helps to improve the stability of the lumbar spine along with improvement of respiratory function. Blowing the balloon requires deep inhalation followed by forceful exhalation.

The main objective of this was to evaluate the effect of 90-90 hip shift hemibridge with balloon exercise on primary dysmenorrhea in obese undergraduate females for pain using VAS and WaLIDD scales. The pain of primary dysmenorrhea was reduced post intervention in this study. Earlier studies have concluded that doing exercise during menstruation reduces the menstrual symptoms especially pain. Exercises during menstruation will 
reduce the intensity as well as the duration of the pain. Till now there are only few literatures which have treated the primary dysmenorrhea in young obese females during menstrual phase of menstrual cycle. However, this exercise was found effective in treating the chronic non specific LBP. This study used this exercise to treat menstrual LBP in obese females.

The study showed significant decrease in VAS scores after performing this exercise for first 3 days during menstruation. The VAS scores were taken first day pre intervention and $3^{\text {rd }}$ day post intervention. Also, other outcome measure used was WaLIDD scale which was taken post intervention on $3^{\text {rd }}$ day and was compared with the previous month score, which showed excellent statistical significance.

After the completion of the study we found that, exercises that provide lumbar stabilization and activation of the core muscles may help to reduce the function of the passive subsystem which increases the ligament laxity and thereby reduces the spinal stability due to hormonal imbalance. Thus this experimental study of 3 sessions leads to the findings that the treatment protocol in the study was significant in reducing pain and improving daily actives as compared to the previous cycle.

\section{CONCLUSION \& LIMITATIONS}

The present study concluded that 9090 supported hip shift with hemibridge with balloon exercise reduces pain in primary dysmenorrhea during menstruation. The limitations of the study were small sample size and long term follow up could not be assessed. For further research purpose large sample size and duration of the intervention can be increased.

\section{ACKNOWLEDGEMENT}

It's my great pleasure and privilege to express my deep- felt gratitude to our respected Principal sir Dr. Ronald Prabhakar and Guide Dr. Archana D. Methe who immensely helped me and rendered their advice, precious time, constant encouragement, knowledge and relevant information regarding my study, and whose suggestion and guidance has enlightened me on this subject. I am also grateful to Dr. Amit Nagrale, Professor, Dep. Of community medicine, Miraj Medical Centre, College of Physiotherapy, Wanless Hospital, for help in the data analysis of this study. I give my sincere gratitude to my subjects those who voluntarily participated in my study.

Above all, I would like to thank my parents for their blessings, love, constant support, affection and encouragement.

Praise and glory to the God almighty who is the source of strength, foundation of my knowledge and the source of inspiration in every walk of life.

\section{Conflict of Interest: None}

\section{Source of Funding: None}

\section{Ethical Approval: Approved}

\section{REFERENCES}

1. Dutta DC. DC Dutta's Textbook of Gynecology Including Contraception. 6th ed. New Delhi: Jaypee Brothers Medical Publishers (P) LTD; 2013:178.

2. Ussher JM, Chrisler JC, Perz J. Routledge International Handbook of Women's Sexual \& Reproductive Health. New York: Routledge; 2020:101-104.

3. Lim JU, Lee JH, Kim JS, et al. Comparison of World Health Organization and AsiaPacific body mass index classifications in COPD patients. International journal of chronic obstructive pulmonary disease. 2017; 12:2465.

4. Singh A, Kiran D, Singh $H$, et al. Prevalence and severity of dysmenorrhea: a problem related to menstruation, among first and second year female medical students. Indian J Physiol Pharmacol. 2008 Oct 1;52(4):389-97.

5. Coco AS. Primary dysmenorrhea. American family physician. 1999 Aug 1;60(2):489.

6. Harel Z. Dysmenorrhea in adolescents. Annals of the New York Academy of Sciences. 2008 Jun;1135(1):185-95. 
7. Marjoribanks J, Proctor M, Farquhar C, et al. Nonsteroidal anti-inflammatory drugs for primary dysmenorrhea. Cochrane Database of Systematic Reviews. 2003(4).

8. Wong CL, Farquhar C, Roberts H, et al. Oral contraceptive pill as treatment for primary dysmenorrhoea. Cochrane Database of Systematic Reviews. 2009(2).

9. Burnett MA, Antao V, Black A, et al. Prevalence of primary dysmenorrhea in Canada. Journal of Obstetrics and Gynaecology Canada. 2005 Aug 1;27(8): 765-70.

10. Agarwal AK, Agarwal A. A study of dysmenorrhea during menstruation in adolescent girls. Indian journal of community medicine: official publication of Indian Association of Preventive \& Social Medicine. 2010 Jan;(1):159.

11. Prabhu S,Nagrale S,Shyam A,Sancheti P. Effect Of Yogasanas On Menstrual Cramps In Young Adults Females With Primary Dysmenorrhea. Int $\mathbf{J}$ Physiother Res. 2019;7(4):3109-12.

12. Mohapatra D, Mishra TA, Behera M, et al. A study of relation between body mass index and dysmenorrhea and its impact on daily activities of medical students. Asian J Pharm Clin Res. 2016;9(3):297-9.

13. Fernández-Martínez E, Onieva-Zafra MD, Parra-Fernández ML. The impact of dysmenorrhea on quality of life among spanish female university students. International journal of environmental research and public health. 2019 Jan;16(5):713.

14. Rai RK, Jaacks LM, Bromage S, et al. Prospective cohort study of overweight and obesity among rural Indian adults: sociodemographic predictors of prevalence, incidence and remission. BMJ Open. 2018;8:e21363.

15. Kulkarni VS, Kulkarni VS, Gaiha R. "Double burden of malnutrition": reexamining the coexistence of undernutrition and overweight among women in India. Int J Health Serv. 2017; 47:108-133.

16. Ju H, Jones M, Mishra GD. Premenstrual syndrome and dysmenorrhea: symptom trajectories over 13 years in young adults. Maturitas. 2014 Jun 1;78(2):99-105.

17. Kafaei-Atrian M, Mohebbi-Dehnavi Z, Sayadi L,et al. The relationship between the duration of menstrual bleeding and obesity- related anthropometric indices in students. Journal of education and health promotion. 2019;8.

18. Mohamed AG, Hables RM. Menstrual Profile and Body Mass Index among Female University Students. American Journal of Nursing. 2019;7(3):360-4.

19. Rad M, Sabzevari MT, Dehnavi ZM. The Relationship between anthropometric index and primary dysmenorrhea in female high school students. Journal of Education and Health Promotion. 2018; 7:34.

20. Omidvar S, Bakouei F, Amiri FN, et al. Primary dysmenorrhea and menstrual symptoms in Indian female students: prevalence, impact and management. Global journal of health science. 2016 Aug;8(8): 135.

21. Shakeri H, Fathollahi Z, Karimi N, et al. Effect of functional lumbar stabilization exercises on pain, disability, and kinesiophobia in women with menstrual low back pain: a preliminary trial. Journal of chiropractic medicine. 2013 Sep 1;12(3): 160-7.

22. Mahendran M. Effectiveness of 90/90 Supported Hip Shift with Hemi Bridge Ball and Balloon Exercises along with Forced Breathing Technique on Improving Pulmonary Function and Reducing Pain in Patients with Chronic Back Pain (Doctoral dissertation, Nandha College of Physiotherapy, Erode).

23. Fernandes J, Chougule A. Effects of Hemibridge with Ball and Balloon Exercise on Forced Expiratory Volume and Pain in Patients with Chronic Low Back Pain: An Experimental Study. International Journal of Medical Research \& Health Sciences. 2017;6(8):47-52.

24. Boyle KL, Olinick J, Lewis C. The value of blowing up a balloon. North American journal of sports physical therapy: NAJSPT. 2010 Sep;5(3):179.

25. Azima S, Bakhshayesh HR, Abbasnia K, Kaviani M, Sayadi M. The effect of isometric exercises on primary dysmenorrhea: a randomized controlled clinical trial. Galen Medical Journal. 2015 Feb 19;4(1):26-32.

26. Teherán AA, Piñeros LG, Pulido F, Guatibonza MC. WalIDD score, a new tool to diagnose dysmenorrhea and predict medical leave in university students. 
Pranali Chougule et.al. Effect of 90-90 supported hip shift hemibridge with balloon exercise on primary dysmenorrhea in obese undergraduate females- an experimental study.

International journal of women's health. 2018;10:35.

27. Heitz NA, Eisenman PA, Beck CL, Walker JA. Hormonal changes throughout the menstrual cycle and increased anterior cruciate ligament laxity in females. Journal of athletic training. 1999 Apr;34(2):144.
How to cite this article: Chougule P, Methe AD, Shah D et.al. Effect of 90-90 supported hip shift hemibridge with balloon exercise on primary dysmenorrhea in obese undergraduate femalesan experimental study. Int $J$ Health Sci Res. 2021; 11(7): 9-16. DOI: https://doi.org/10. 52403/ijhsr.20210702 